\title{
Towards an International Year of Sound
}

The United Nations (UN) observes designated days, weeks, years, and decades to mark particular events, or topics, in order to promote, through awareness and action, the objectives of the UN. Although the majority of observances have been established by resolutions of the UN General Assembly, some have been designated by UN specialized agencies, such as UNESCO, UNICEF, FAO, etc., when they concern issues that fall within the scope of their competencies.

Initiated by the International Commission on Acoustics (ICA), the International Year of Sound (IYS) is planned to be a global initiative to highlight the importance of sound in all aspects of life on earth. Since this initiative strongly agrees with the main objective of our own organization, the International Institute of Acoustics and Vibration (IIAV) is one of the founding supporters of the IYS providing seed funding. The IYS will consist of coordinated activities at all levels, aiming to stimulate the understanding and awareness throughout the world of the important role that sound and hearing plays in all aspects of society. Specifically, the IYS will focus the world on how sound is an integral part of society and has inspired art, music, literature, and philosophy across the centuries. The year will also promote the applications of science and technology in dealing with sound and vibration and using it for the benefit of mankind. Considerable work and negotiations with international bodies including the United Nations Educational, Scientific and Cultural Organization (UNESCO) have been necessary to achieve the IYS proposal officially. ICA will be seeking the support from the all member organizations in this quest.

There are already some important acoustics-related dates that are celebrated around the world, and they may serve as a basis for the IYS. Probably the oldest is the International Noise Awareness Day (INAD) that was established by the Center of Hearing and Communication (known years ago as the League for the Hard of Hearing) in 1996 to encourage people to do something about bothersome noise where they work, live, and play. This idea, which began as a local initiative, has become truly international. The INAD is commemorated each year on the last Wednesday of April. Many scientific societies all over the world have started during the last decade to organize INAD specific events in their countries. These mainly address young people, who are among the most sensitive persons in our society, but also the general public by spreading of newsletters, and the organization of lectures, seminars and workshops.

On the other hand, 2018 was the 15th year of La Semaine du Son (the week of sound) in Paris (21-27 January), a week having events dealing with each of the following five themes: health, environmental sound, recording techniques and sound diffusion, relationship between pictures and sound, and music and sound expression. While the concept commenced in
France, there are now events in several other countries. The five main themes of La Semaine du Son became the basis for the development of the Charter of Sound that was presented to UNESCO on 18 Jan 2016. Following on from the declaration of the Charter, the Executive Committee of UNESCO adopted the resolution 39C/49 "The importance of sound in today's world: promoting best practices” on 31 October 2017.

More recently, the World Health Organization (WHO) has promoted the World Hearing Day, celebrated on 3 March each year since 2007 to raise awareness on how to prevent deafness and hearing loss and promote ear and hearing care across the world. The day was previously known as the International Ear Care Day. Each year, WHO decides the theme and develops a brochure on the topic based on the best available scientific evidence. This year, the theme will be "Hear the future", and the day will draw attention to the anticipated increase in the number of people with hearing loss around the world in the coming decades. In recent years, an increasing number of UN member states and other partner agencies have joined the World Hearing Day by organizing a range of activities and events in their countries.

Originally, ICA submitted a prospectus where 2019 was the preferred candidate for the IYS. As the president of the IIAV, I attended two ICA board meetings held in Boston, Massachusetts, in 2017 (26 and 28 June). There, the ICA president informed us about the IYS status. The plan for the year 2019 become difficult since we would have a strong competition with the proposal of the International Year of the Periodic Table of Chemical Elements, IYPT 2019, which will coincide with the 150th anniversary of the discovery of the Periodic System by Dmitry Mendeleev in 1869, and the Centenary of the International Union of Pure and Applied Chemistry. In fact, IYPT 2019 was proclaimed by the UN 74th Plenary Meeting on 20 December 2017. Now, the targeted year for the International Year of Sound will be 2020 (IYS 2020). ICA has already secured the domain "sound2020.org" in anticipation of year 2020 being named the IYS.

Undoubtedly, the declaration of an IYS will provide a focus that will encourage transfer of knowledge on creating, controlling, hearing, and using sound in nature, in the built environment and in all aspects of our life. I invite all acousticians to support the ICA efforts in achieving this objective and help spreading the word among your peers.

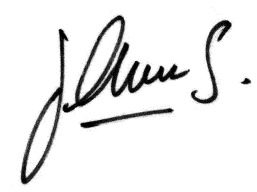

\section{Jorge P. Arenas}

President IIAV

Editor-in-Chief IJAV 